Short Communication

\title{
Improved Surface Properties for Nanotube Growth on Selective Laser Melted Porous Ti6Al4V Alloy via Chemical Etching
}

\author{
Xiaoqing Ni, Liang Zhang*, Wenheng Wu, Jia Song, Beibei He, Dexiang Zhu \\ Shanghai Engineering Research Center of 3D Printing Materials, Shanghai Research Institute of \\ Materials, Shanghai 200437,China \\ *E-mail: liangustb@126.com
}

doi: $10.20964 / 2019.06 .14$

Received: 25 Janaury 2019 / Accepted: 5 March 2019 / Published: 10 May 2019

\begin{abstract}
In this work, porous Ti6Al4V components with a $400 \mu \mathrm{m}$ interval were prepared by selective laser melting (SLM), one of most popular powder-bed additive manufacturing technologies for metallic alloys, there were many un-melted powders adhered to the as-received substrate framework. To improve the bio-functional property, surface treatment for this complex structure must be taken into consideration and chemical etching for proper time can remove the trapped powders. Anodic oxidation experiments showed that non-uniform nanotubes grew on the trapped powders, while nanotubes grew uniformly on the chemical etched substrate and the diameter of nanotubes was about $100 \mathrm{~nm}$ all over the place. The electrochemical experiments and cell proliferation results all showed that the chemical etching method can improve the corrosion resistance and biocompatibility of the SLM porous Ti6A14V.
\end{abstract}

Keywords: Ti-6Al-4V; Selective laser melting; Nanotube; Porous materials; Chemical etching

\section{FULL TEXT}

(C) 2019 The Authors. Published by ESG (www.electrochemsci.org). This article is an open access article distributed under the terms and conditions of the Creative Commons Attribution license (http://creativecommons.org/licenses/by/4.0/). 